\title{
Faktör Hareketliliği Bağlamında Göç ve Doğrudan Yabancı Yatırımların Ticarete Etkisinin Karşılaştırmalı Analizi
}

\section{A Comparative Analysis of the Effect of Migration and Foreign Direct Investment on Trade in the Context of the Factor Mobility}

\section{Hande Aksöz Yılmaz' 무}

Öz

Bu çalışma faktör hareketliliği çerçevesinde göç ve doğrudan yabancı sermaye yatırımlarının ticaret üzerindeki etkisini karşılaştırmalı olarak analiz etmeyiamaçlamaktadır. Çalışma, Türkiye'nin en büyükticaret partnerlerinden olan Almanya, Fransa, İtalya, Birleşik Krallık ve ABD'ye giden göçmenlerin, bu ülkelerden Türkiye'ye gelen doğrudan yabancı sermaye yatırımlarının ve ticarete etki eden döviz kuru, yabancı istihdamı, küreselleşme indeksi ve politik istikrar indeksi değişkenlerinin 2000-2018 yılları arasındaki yıllık verilerini kapsamaktadır. Ticaret-Göç ve Ticaret-Doğrudan yabancı sermaye yatırımlar bağlantılarının analizinde dinamik panel veri modeline dayalı Genelleştirilmiş Momentler Tahmincisi (GMM) tahmin yönteminden faydalanılmaktadır. Çalışma sonucunda elde edilen bulgular, 2000-2018 yıllarında Türkiye'den giden göçmenlerin, Türkiye'ye gelen yabancı yatıımlara göre ticaret üzerinde daha fazla etkiye sahip olduğunu ortaya koymaktadır. Ayrıca, geleneksel dış ticaret teorilerinin temel varsayımları geride bırakıldığında, faktör hareketleri ile ticaretin tamamlayıcı olduğunu vurgulayan literatürle paralel sonuçlar elde edilmektedir.

\section{Anahtar Kelimeler}

Dış ticaret, Doğrudan yabancı yatırımlar, Uluslararası faktör hareketliliği, Göç

\begin{abstract}
This study investigates the effect of immigration and foreign direct investment on trade within the framework of factor mobility. Hence, we used annual data, spanning the period of 2000-2018, and immigration flows to Turkey's major trade partners (Germany, France, Italy, UK, and the United States). The inward foreign direct investment flows to Turkey from these countries. However, exchange rates, foreign employment, globalization index, and political stability index variables affect trade. The findings show that migration flows from Turkey to five countries and have more impact on trade, compared to inward foreign direct investment to Turkey over
\end{abstract}

1 Sorumlu Yazar: Hande Aksöz Yılmaz (Dr.), Kırşehir Ahi Evran Üniversitesi, İktisadi ve İdari Bilimler Fakültesi, İktisat Bölümü, Kırşehir, Türkiye. E-posta: hande.yilmaz@ahievran.edu.tr ORCID: 0000-0002-1115-7535

Atıf: Aksoz Yilmaz, H. (2021). Faktör Hareketliliği Bağlamında Göç ve Doğrudan Yabancı Yatırımların Ticarete Etkisinin Karşılaştırmalı Analizi. Journal of Social Policy Conferences, 81, 127-150. https://doi.org/10.26650/jspc.2021.81.903847 
the period of 2000-2018. Furthermore, when the fundamental assumptions of traditional foreign trade theories are ignored, parallel results are obtained, indicating that factor movements and trade are complementary.

\section{Keywords}

Foreign trade, Foreign direct investment, International factor mobility, Migration 


\section{Extended Summary}

The Heckscher-Ohlin Theorem states that specialization in countries after free foreign trade (FD) shapes the factor demand and factor prices of those countries. Under the basic assumptions of traditional foreign trade theories, International Factor Mobility (IFM) arises from different international prices. The fact that a labor-abundant country specializes in labor-intensive goods and trading increases the demand for labor in such countries. The demand for scarce capital and prices also decreases. Under factor mobility, labor in other countries with relatively lower returns moves to the country where the price is higher.

Furthermore, wages decrease as the labor supply in these countriesexceed their demands. The convergence of factor prices among relevant FD countries reduces the incentive to replace production factors (Samuelson, 1949, p. 166). Traditional foreign trade theories emphasize the fact that "factor movement" and trade are interchangeable, explaining the effect of factor mobility on trade through factor price convergence. However, Mundell (1957) stated that; formal or informal trade restrictions, foreign trade costs, and certain obstacles in the mobility of production factors can change the relationship between FD and IFM. Later, he shed light on Markusen (1983) and other theoretical approaches, emphasizing the complementary nature of this relationship. When the basic assumptions of traditional foreign trade theories are ignored, the alternative hypothesis must be accepted to demonstrate how factor movements and trade complement each other. Therefore, an applied method is created based on the hypothesis of Markusen (1983) expressing the relationship between factor mobility and trade.

This study examines factor mobility based on immigration and Foreign Direct Investment (FDI). However, since labor movement is the main subject of migration flows, labor mobility has been studied in the context of migration. Capital movements are handled specifically for FDI, which do not include financial investments. The impact of migration and foreign investment flows on trade is investigated in Germany, the US, Italy, France, and the UK, which are Turkey's largest trade partners over the period of 2000-2018. This study comparatively analyzes the impact of immigrant flows from Turkey and inward FDI to Turkey on total trade between these countries and Turkey. The study employs the panel GMM estimation method, which presented an efficient output because the past observation values of the dependent variable are instrumented 
to control an endogenous relationship. Labor and capital movements between the source and destination countries are effective in trade through choice and network channels. The study explains the effect of labor and capital mobility on trade with the help of two models. Model-1 explains the effect of immigration on trade and Model-2 explains the effect of capital mobility on trade. Model-1 results show that trade is explained by past trade value, immigrant flows from Turkey, distance, exchange rate, political stability, and the level of globalization. Model-2 results show that trade is explained by past trade value, FDI, and exchange rates. Model-1 and Model-2 results reveal which factor mobility is more effective in total trade between Turkey and these countries. The immigrant flows from Turkey have a greater effect on total trade between Turkey and these countries than inward FDI to Turkey. The estimates provided by the dynamic panel data model (Model-1) are in line with Gould (1994), Hied and Ries (1998), Dunlevy and Hutchinson (1999), Dunlevy and Hutchinson (2001), Rauch and Trindade (2002) Combes et al. (2002), Girma and Yu (2002), Wagner et al., (2002) and Egger et al. (2011). The finding obtained from Model-2 about FDI's positive effects on trade coincides with the findings of Kojima (1991), Buigues and Jacquemin (1994), Liu and Graham (1998), Pantulu and Poon (2003), and Aizenmana and Noyb (2006).

In Turkey's 11th Development Plan, FDIs are directed to the industrial sector to increase the share of new investments. Despite the slowdown, Turkey has risen ten places to be 33rd among 190 countries in the World Bank's "2020 Ease of Doing Business Index," owing to the weakening global economy and the threat of the Covid-19 pandemic. It is also important to evaluate the tradeenhancing effect of FDI at the point of directing new investments that create high value to the manufacturing industry of Turkey. Furthermore, as a result of globalization, increased migration becomes an important part of the labor supply. Policymakers should consider the positive impact of migration on Turkey's FD, particularly exports. Keeping network channels open through individual and corporate organizations with outgoing immigrants from Turkey will contribute to increasing trade and exports for the ultimate economic goals of Turkey. 


\section{Faktör Hareketliliği Bağlamında Göç ve Doğrudan Yabancı Yatırımların Ticarete Etkisinin Karşılaştırmalı Analizi}

Küreselleşmenin tüm dünya ekonomilerinde ortaya çıkardığı etkiler, üretim faktörlerinin hareketliliği üzerinde de etkili olmuştur. Dış ticarette mal hareketlerinin serbestleşmesi sonrasında ülkeler arasındaki emek hareketliliği de aşamalı olarak artmıştır. Ülkeler arasındaki ticarete dayalı mal hareketliliği, yapısı gereği emek hareketliliğinden farklılık göstermekteyse de, birbirleri üzerindeki etkileri uzun yıllardır dış ticaret literatürünün tartışma odağında yer almaktadır. Dış ticaret ve faktör hareketliliği ilişkisi üzerine teorik tartışmalar, Heckscher-Ohlin'in Faktör Donatımı Teorisi'ne dayalı olarak Stolper ve Samuelson tarafından geliştirilen Faktör Fiyatlarının Eşitlenmesi Teorisi ile başlamaktadır. Bu teori, uluslararası faktör hareketliliğinin uluslararası faktör fiyatlarındaki farklılıklar temelinde gerçekleştiğini vurgularken, ülkelerin dış ticarette uzmanlaştığı malların üretiminde yoğun olarak kullanılan faktörün fiyatının artacağını varsaymaktadır. Dolayısıyla diğer ülkelerdeki bu faktör, nispi olarak fiyatının düşük olduğu bölgelerden fiyatının yüksek olduğu bölgelere hareket etmektedir. Söz konusu faktörün fiyatının yüksek olduğu bölgede ilgili faktör arzının faktör talebini aşmasıyla faktör fiyatı azalma eğilimine girmektedir ki, bu mekanizma uluslararası ticaret sonrasında faktör fiyatlarının yakınsamasını ifade etmektedir. Geleneksel dış ticaret teorileri, faktör hareketliliğinin ticaret üzerinde doğurduğu etkiyi faktör fiyatlarının birbirine yakınsaması temelinde açıklayarak aralarındaki ilişkinin ikame olduğuna vurgu yapmaktadır. Ancak Mundell (1957), geleneksel ticaret teorileriyle benzer sonuçlar ortaya koymasına rağmen, formel ya da informel ticari kısıtlamalar, dış ticaret maliyetleri ve üretim faktörlerinin tam hareketli olmasının önündeki bir takım engellerin dış ticaret ve faktör hareketliliği ilişkisinde değişiklik yaratabileceğini belirterek, sonrasında Markusen (1983) başta olmak üzere bu ilişkinin tamamlayıcılığına vurgu yapacak bir çok teorik yaklaşıma 1şık tutmuştur. Mundell (1957), statik ticaret modellemelerinde ticaretten faktör hareketliliğine doğru tamalayıcılık ilişkisi öngörürken; Markusen (1983), faktör hareketliliğinden ticarete doğru ilerleyen mekanizmaya dikkat çekmektedir. Geleneksel dış ticaret teorilerinin temel varsayımları geride bırakıldığında faktör hareketleri ile ticaretin tamamlayıcılığını ortaya koyan alternatif hipotez geçerliliğini kabul ettirmiştir. Dolayısıyla çalışmada, Markusen (1983)'in faktör hareketliliği ve ticaretin tamamlayıcı ilişkisini ifade eden hipotezine dayalı olarak uygulamalı model oluşturulmuştur. 
Bu çalışmada faktör hareketliliği emek ve sermaye hareketliliği temelinde göç ve doğrudan yabancı sermaye yatırımlarına dayalı olarak incelenmektedir. Göç ve doğrudan yabancı sermaye hareketlerinin ticaret üzerinde doğurduğu etkiler Türkiye'nin en büyük ticari partner ülkeleri olan Almanya, ABD, İtalya, Fransa ve Birleşik Krallık ülkeleri için incelenmiştir. Bu çalışmanın amacı, Türkiye'nin en büyük ticari partneri olan ülkelere Türkiye'den giden göçmenlerin ve bu ülke grubundan Türkiye'ye gelen Doğrudan Yabancı Sermaye Yatırımlarının (DYY) Türkiye ile bu ülkelerin toplam ticareti üzerindeki etkilerini karşılaştırmalı olarak incelemektedir. Buradan hareketle çalışma “2000-2018 yıllarında Türkiye'nin en büyük ticari partner ülkelerine Türkiye'den gerçekleşen göçün ve söz konusu ülkelerden Türkiye'ye gelen DYY'lerin Türkiye ve ilgili ülkeler arasındaki toplam ticareti üzerindeki etkileri ne olmuştur" sorusunun cevabını araştırmaktadır. Bu bağlamda çalışmanın başlıca hipotezleri şu şekilde oluşturulmuştur: Hipotez-1: Türkiye'nin en büyük ticari partneri olan 5 ülkeye Türkiye'den gerçekleşen göç, Türkiye'nin ilgili ülkeler ile olan toplam ticaretini artırmıştır. Hipotez-2: Türkiye'nin en büyük ticari partneri olan 5 ülkeden Türkiye'ye gerçekleşen DYY'ler Türkiye'nin ilgili ülkeler ile olan toplam ticaretini artırmıştır. Bu amaç, hipotez ve çalışma sorusu perspektifinde, çalışmanın öncelikli hedefi, göç-ticaret ve DYY-ticaret arasındaki ilişkiyi dinamik panel veri modeline dayalı Genelleştirilmiş Momentler Tahmincisi (GMM) tahmin yöntemi ile test etmektir.

$\mathrm{Bu}$ çalışma ticaret ve faktör hareketliliği ilişkisini ortaya koyan diğer çalışmalara ek olarak üç farklı katkı sunmaktadır. Birincisi, faktör hareketliliği ile ticaretin ikame ya da tamamlayıcılık ilişkisine yönelik teorik tartışmaları tarihsel gelişim perspektifinde ve teorisyenlerin varsayımları temelinde açıklamaktadır. İkincisi, Türkiye'den en büyük ticari parner ülkelere giden göçmenlerin ticaret üzerindeki etkisi göç akımlarını ve ticareti belirleyen diğer unsurlar da dikkate alınarak dinamik panel veri modeliyle açıklanmaktadır. Üçüncü olarak, sermayenin hareketliliği yatırımlar bağlamında düşünülerek, Türkiye'nin en büyük ticari partner ülkelerinden gelen doğrudan yabancı yatırımların karşılıklı ticaret üzerindeki etkisi dinamik panel veri modeli ile açıklanmaktadır. Bu çalışma, doğrudan yabancı yatırımlar ve göç hareketlerinin ticaret üzerindeki etkilerinin iki ayrı model yardımıyla ortaya konulması ve iki farklı model sonuçlarının karşılaştırılması açısından önemlidir. 


\section{Teorik ve Uygulamalı Literatürün İncelemesi}

Heckscher-Ohlin Teoremi, serbest ticaret sonrasında ülkelerde ortaya çıkan uzmanlaşmanın, söz konusu ülkelerin faktör talebini ve faktör fiyatlarını şekillendirdiğini ifade etmektedir. Geleneksel diş ticaret teorilerinin temel varsayımları altında uluslararası faktör hareketliliği, uluslararası faktör fiyatlarının farklılı̆̆ından kaynaklanmaktadır. Nitekim emek bol bir ülkenin emek yoğun mal üzerinde uzmanlaşıp ticarete başlaması bu ülkede emek talebini artırırken, kit olan sermayenin talebini azaltmakta ve fiyatını düşürmektedir. Faktör mobilitesi varsayımı altında, nispi olarak daha düşük getiriye sahip olan diğer ülkelerdeki emek, fiyatının yüksek olduğu ülkeye hareket etmektedir. Sonrasında ise bu ülkedeki emek arzının talebini aşması nedeniyle ücretler azalmaya başlamaktadır. Böylelikle dış ticaret yapan ilgili ülkeler arasındaki faktör fiyatlarının birbirine yakınsaması üretim faktörlerinin yer değiştirmesinin teşvikini azaltmaktadır (Samuelson, 1949, s. 166). Geleneksel dış ticaret teorileri ticaret ve faktör hareketliliği arasındaki teorik bağlantıyı faktör fiyatlarının eşitlenmesi mekanizmasına dayalı olarak açıklamaktadır. Ancak ticaret kısıtlamaları, taşıma maliyetleri ve kısmi faktör hareketliliği gibi pek çok unsur, ticaret ve faktör hareketliliği ilişkisinin ikame olmaktan çok tamamlayıcı olduğunu ima etmektedir. Mundell (1957, s. 321322)'in, iki ülkeli, iki mallı (emek yoğun mal ve sermaye yoğun mal) ve iki faktörlü (emek ve sermaye) ticaret modellemesinde faktör mobilitesinin bulunduğu ve bulunmadığı, ticaret kısitlamasının bulunduğu ya da bulunmadığı hallerde faktör hareketleri ve ticaret ilişkisini statik olarak incelemiştir. Ticaret engellerinin artmasının faktör hareketlerini uyardığını ve faktör hareketlerine yönelik kısıtlamalardaki artışın da ticareti canlandırdığını ifade ederek ikame ilişkiye vurgu yapmıştır. Faktör fiyatlarının eşitlenmesi mekanizması ya da Mundell (1957, s. 32-333)'in statik ticaret modellemelerinde ticaretten faktör hareketliliğine doğru bir ilişki gözetilirken; Markusen (1983), faktör hareketliliğinden ticarete doğru ilerleyen mekanizmaya dikkat çekmiştir. Bu bağlamda Markusen (1983), bir ülkeye sermaye ithalatı arttığında, o ülkede sermaye yoğun malların ihracatının artacağını vurgulamaktadır. Diğer bir deyişle faktör ticareti ile mal ticareti tamamlayıcı olmaktadır. Sermaye talebi inelastik ve sermaye-emek birlikte hareket ederse sermaye ithalatının azalacağ1 ve mal ticaretinin faktör ticaretini ikame edeceği sonucuna varmaktadır. Ancak, sermaye talebi esnek olup, sermaye ve emek birlikte hareket etmiyorsa mal ve faktör ticareti tamamlayıcı olma eğilimindedir. Mundell (1957)'in, mal ve 
faktör hareketleri ilişkisini açıklayan teorik modellemesi, ticaret ve faktör hareketliliğinin tamamlayıcılı̆̆ hipotezi üzerine pek çok araştırma için dayanak teşkil etmiştir. Baldwin ve Venables (1994, s. 287), iki ülkeli, 3 faktörlü (sermaye, vasıflı emek ve vasıfsız emek) iki sektörlü (tarım ve imalat sektörü) yapıda, mal ticaretinin genel olarak faktör fiyatı eşitlemesini sağlamak için yeterli olmadığını ifade etmektedir. Serbest ticaret varsa ve vasıflı emek ve sermaye serbestçe uluslararası olarak hareket ediyorsa, bu hareketlilik faktör fiyatının eşitlenmesini sağlar, ancak uzun dönemde ayarlama maliyetleri ve buna bağlı sermaye ve işgücü hareketliliğinin dinamikleri açık hale getirilmediği için bu denge belirsizdir (Baldwin ve Venables, 1994, s. 298).

Faktör hareketleri ve ticaret arasındaki ilişkiyi açıklayan teorik ve uygulamalı literatür, ilişkinin ikame ya da tamamlıyıcılığ hipotezi noktasında ortak bir kanıya sahip olmamakla beraber, güncel uygulamalı çalışmalar ilişkinin tamamlayıcılı̆̆ını temel alan modellemelere yönelmiştir. Faktör hareketliliği bağlamında emek ve semayenin ticaret ile olan ilişkisi pek çok çalışmada birlikte değerlendirilmemiştir. Yaygın literatür göç ve ticaret ilişkisini açıklamaya yönelik çalışmalardan oluşmaktaysa da (Gould, 1994; Hied ve Ries, 1998; Dunlevy ve Hutchinson, 1999; Dunlevy ve Hutchinson, 2001; Rauch ve Trindade, 2002; Combes vd. 2002; Girma ve Yu, 2002; Wagner vd., 2002; Egger vd., 2011), ticaret ve doğrudan yabancı sermaye yatırımları arasındaki ilişkiyi inceleyen çalışmalar da bulunmaktadır (Kojima, 1991; Buigues ve Jacquemin, 1994; Liu ve Graham, 1998; Pantulu ve Poon, 2003; Aizenmana ve Noyb, 2006) Bu doğrultuda, faktör hareketliliği ve ticaret arasındaki ilişkiyi araştıran literatür: öncelikli olarak göç ve ticaret arasındaki ilişkiyi açıklayan; sonrasında ise doğrudan yabancı sermaye yatırımları ve ticaret arasındaki ilişkiyi araştıran çalışmalar olmak üzere iki kısımda incelenmektedir.

Göç ve ticaret ilişkisinin tamamlayıcı olduğu hipotezinden hareketle oluşturulan modellerde göçün ticaret yaratıcı etkisi ülkeler özelinde test edilmiştir. Göç eden bireyler, bir trafatan kendi anavatanlarına özgü bireysel, kurumsal, politik, kültürel ve toplumsal edinimleri ile birlikte göç ederken; diğer taraftan göç etmiş bu bireylerin kaynak ülkeleri ile olan formel ve informal bağları devam etmektedir. Giden göçmenlerin kaynak ve hedef ülke arasındaki ticaret artırıcı yönü tercih ve network olmak üzere iki kanaldan gerçekleşmektedir. Göçmenlerin anavatanları olan kaynak ülke ile gittikleri ülkeler olan hedef 
ülkeler arasındaki ticari ilişkiler, göç etmiş bireylerin kaynak ve hedef ülke arasında kurduğu network kanalıyla gelişme gösterebilmektedir. Nitekim kaynak ülkenin dili, kültürü, iş yapma biçimi, ticari ilişki gelenekleri, sözleşmelerin güvenilirliği ve işlem-zaman maliyetinin azaltılması noktasında göçmenler önemli bir rol üstlenmektedir. Göç eden bireyler hedef ülkelere vardıklarında en azından ilk aşamada anavatanlarındaki alışılagelmiş tüketim kalıplarını devam ettirme eğiliminde olmaktadır. Hedef ülkenin bu göçmenler nedeniyle kaynak ülkeye olan ithalat talebi artmaktadır. Hedef ülke vatandaşlarının göçmenlerin tükettiği mallara oluşturduğu farkındalık ile ek bir tüketim talebi de meydana gelmektedir ki, bu durum göçmenlerin ticareti tercih kanalıyla etkilemesini ifade etmektedir. Göç eden bireylerin hedef ülkenin ithalatını daha fazla etkilemesi tercih kanalının etkinliğini; ihracat üzerindeki etkisi ise, network kanalının etkinliğini göstermektedir (Gould, 1994, s. 314). Göçün ticareti hangi kanaldan etkilediğinin tespiti oldukça karmaşı olsa da, mevcut literatür çoğunlukla network kanalıyla ortaya çıktığını ifade etmektedir. Rauch and Trindade (2002, s. 128-129), 63 farklı ülkeye göç etmiş aynı etnik kökene sahip Çin vatandaşlarının ticaret üzerinde network ve sosyal ağlar kanalıyla etkiler doğurduğunu ve ticaret engellerinin aşılabildiğini ortaya koymuştur. Ayrıca göç akımının olduğu iki ülkenin sosyal ve politik kurumlar açısından benzerlik düzeyi arttıkça, karş1lıklı işlem maliyetlerinin düşmesine bağlı olarak ticaret artmaktadır (Girma ve Yu, 2002, s. 123). Dil, iş kültürü, sosyal kurumlar, tarihsel bağ ve hukuk sistemleri gibi çok fazla benzer yönleri bulunan bölgeler arasındaki göç hareketleri ticaret üzerinde daha fazla etkili olmaktadır (Combes vd., 2005, s. 17).

Hedef ülke ile kaynak ülke arasında ticarete konu olan mal grupları açısından düşünüldüğünde, farklılaştırılmış mallarda göçmenlerin bilgisine duyulan ihtiyaç homojen mallardakinden daha yüksek tahmin edilmektedir. Gould (1994, s. 311), göç eden bireylerin tüketim mallarının ticareti üzerindeki etkisinin üretim mallarınınkinden daha yüksek olduğunu vurgulamıştır. Benzer biçimde, Dunlevy ve Hutchinson (2001, s. 32), göç eden bireylerin ara mal ve nihai mal ithalatını hammadde ithalatından daha fazla etkilediği sonucuna ulaşmıştır.

Göç eden bireylerin kaynak ve hedef ülke arasındaki ticaret artırıcı etkisi kısa ve uzun dönemde değişkenlik gösterebilmektedir. Russell ve Teitelbaum (1992) ve Martin (1993), göç hareketlerine bağlı olarak kısa ve orta vadede 
ticaret ile göç arasında tamamlayıcı; ancak uzun dönemde ikame ilişkisinine dönüştügünü ifade etmektedir. Uzun dönemde iki ülke arasındaki gelir farklılıklarının azalması göçün aşamalı olarak azalmasına neden olmaktadır.

Vernon (1966) tarafindan geliştirilen Ürün Dönemleri Teorisi, uluslararası ticareti yenilikçi ve taklitçi ülkeler bağlamında açıklarken, yenilikçi ülkenin inovatif süreci nasıl başlattığı ve bunların aşamalarını vurgulamıştır. Ürünün dönemleri aşamalarından birisi de maliyetlerinin azaltılması bağlamında ticaret yapılan ülkelere DYY kanalıyla bu ürünün üretiminin taşınmasıdır. İhracat ve DYY arasındaki ikame ilişkinin teorik altyapısı dolaylı yoldan da olsa Vernon (1966) tarafından belirtilmiştir. Vernon (1966)'un, geleneksel dış ticaret teorileri varsayımlarına dayalı olarak ifade ettiği ticaret ve DYY ilişkisi, Helpman ve Krugman (1985)'nin ölçek ekonomikeri ve eksik rekabet piyasa koşulları varsayımlarıyla yeniden şekillenmiştir. Ancak, Helpman ve Krugman (1985), çok uluslu şirket operasyonlarının endüstriler arasındaki ticaretten daha çok endüstri içi ticareti teşvik ettiğini vurgulamaktadır. Kalkınmaya dayalı yaklaşımları ile teorik bulgular sağlayan Kojima (1978), ticaret ve ihracat arasındaki ikame ilişkiye imada bulunmuştur. Daha sonra Kojima (1991) çalışmasında, Japonya'nın Asya ve Latin Amerika'daki yatırımlarının ticaret artırıcı etkisini ortaya koymuştur. Ticaret ve doğrudan yabancı sermaye yatırımları arasındaki ikame ya da tamamlayıcılık ilişkisi, doğrudan yabancı yatırımın gitmiş olduğu ülke ve kaynak ülkesi arasındaki üretim ve üretim sonrasındaki aşamalarındaki yapılanması ile doğrudan ilintilidir. A ülkesinin B ülkesinden c malını ithal ettiği varsayılırsa; B ülkesinden Aülkesine gelen bir doğrudan yabancı yatırım, Aülkesinin ithal ettiği malın artık yurtiçinde üretilmesine bağlı olarak, B ülkesinden yapılan ithalatın ikamesi durumuna gelmektedir. Ancak doğrudan yabancı yatırım yapan bir firmanın yerli operasyonları, hedef ülke operasyonları ile dikey olarak bağlantılı olabilmektedir; öyle ki A ülkesine B ülkesince yapılan doğrudan yabancı yatırımdaki bir artış, B ülkesinin ara mallara olan talebini artırmaktadır. Ayrıca, DYY sonrası süreçlerinde gerekli olan pazarlama ve dağıtım yetenekleri, kaynak ülke operasyonlarının, DYY yokluğunda ulaşamayacağı nihai mal ve hizmetleri müşterilere ihraç etmesini sağlamaktadır. Bunlardan herhangi birinin gerçekleştiği ölçüde, DYY ve ihracat tamamlayıcı olmaktadır (Liu ve Graham, 1998).

Çok uluslu firmalar gittiği ülkeye daha büyük pazar payını mümkün kılan ve dolayısıyla bu firmaların faaliyet gösterdiği pazarlarda hem ticareti hem de yatırımı artırabilecek fikri mülkiyet avantajlarına (teknolojiler ve ticari markalar) 
sahiptir (Brainard, 1995). Yine Buigues ve Jacquemin (1994), Avrupa Birliği’ne ABD ve Japonyadan gelen doğrudan yabancı yatırımların ticaret üzerindeki etkisini karşılaştırmalı olarak analiz ettiğinde, iki ülke için de ilişkinin tamamlayıcı olduğu sonucuna ulaşmıştır. Benzer şekilde Graham (1998), Pantulu ve Poon (2003) ABD ve Japonya için; Liu ve Graham (1998) Tayvan ve Güney Kore için giden doğrudan yabancı yatırım ile ticaret arasında tamamlayıcı ilişkinin var olduğunu bulmuştur. Ancak Güney Kore için ithalatta değil ihracatta tamamlayıcılık ilişkisi vurgulanmıştır. Diğer taraftan doğrudan yabancı yatırımlar yalnızca ticaret üzerinde etkiler doğurmamaktadır ve ticaret de doğrudan yatırımları etkilemektedir. Aizenmana ve Noyb (2006), doğrudan yabancı yatırımlardan ticarete doğru olan nedenselliğin daha büyük olduğunu ortaya koymaktadir.

Göç ve doğrudan yabancı sermaye yatırımları ticaret üzerinde etkiler doğurduğu gibi doğrudan yabancı sermaye yatırımları, göç ve ticaret arasında da çoklu bir ilişki bulunabilmektedir. Nitekim, Gonzalez ve Maloney (2005), NAFTA (Kuzey Atlantik Serbest Ticaret Anlaşması)'nın ABD ve Meksika arasındaki göç ve doğrudan yabancı sermaye yatırımlarının birbiri üzerindeki etkilerini ortaya koymaktadır.

\section{Model ve Yöntem}

Faktör hareketliliği bağlamında göç ve doğrudan yabancı sermaye yatırımlarının ticaret ile olan ilişkisi uzun süredir literatürde tartışılmaktadır. Uluslararası faktör hareketliliği esas alındığında çoğunlukla emek ve semaye olmak üzere iki temel faktör dikkate alınmaktadır. Göç eylemi, genellikle insanın sahip olduğu temel faktör olan emek faktörünün hareketliliğini ifade etmektedir. Küreselleşmenin etkisiyle sermayenin hareketliliğindeki artış hızı emek hareketliliğinden çok daha yüksektir. Emeğin hareketliliği sermayeden çok daha eskiye dayanmaktaysa da, geleneksel diş ticaret teorilerine göre sermayenin hem sektörler hem de ülkeler arasındaki mobilitesi emek mobilitesinden daha yüksek kabul edilmiştir. Ülkelerin birbirleriyle olan ticareti çok fazla makro ekonomik unsura bağlı olarak değişmektedir. Yine ülkeler arasındaki faktör hareketliliği ülkelerin birbirleriyle olan ticaretlerini etkilemektedir. Gerek tercih gerekse de network kanalı kaynak ve hedef ülkeler arasında emek ve sermayenin ticaret üzerinde etkili olmasına olanak tanımaktadır. Emek ve sermayenin ticaret üzerindeki etkisi iki model yardımıyla 
açıklanmıştır. 'Model-1 göçün ticarete etkisini, Model-2 ise sermaye hareketlerinin ticaret üzerindeki etkisini açıklamaktadır. Model-1 ve Model2'den elde edilen sonuçlar Türkiye'nin ilgili ülkelerle ticaretinde hangi faktörün hareketliliğinin daha etkili olduğunu ortaya koymaktadır. Türkiye'nin en çok ticaret yaptığ 5 ülke olan; Almanya, Fransa, İtalya, Birleşik Krallık (UK) ve Amerika Birleşik Devletleri (ABD)'ye Türkiye'den giden göçmenler ve söz konusu ülkelerden gelen doğrudan yabancı sermaye yatırımlarının ticaret üzerindeki etkisi dinamik panel veri modeline dayalı GMM tahmin yöntemiyle analiz edilmiştir.

Model-1: Lntrade $_{\mathrm{ijt}}=\alpha_{0} \operatorname{Lnmig}_{\mathrm{ijt}}+\beta_{0} \operatorname{Lntrade}_{\mathrm{ij}(\mathrm{t}-1)}+\beta_{1} \operatorname{Lnmig}_{\mathrm{ij}(\mathrm{t}-1)}+\beta_{2} \operatorname{Lnexc}_{\mathrm{it}}-\beta_{3}$ Lndist $_{\mathrm{ij}}+\beta_{4}$ Lnempf $_{\mathrm{jt}}+\beta_{5} \operatorname{Lngdp}_{\mathrm{it}}+\beta_{6} \operatorname{Lnkof}_{\mathrm{jt}}+\beta_{7} \operatorname{Lnpol}_{\mathrm{jt}}+\mathrm{eu}+\mathrm{D}_{2008}+\varepsilon_{\mathrm{ijt}}$

Model-2: $\operatorname{Lntrade}_{\mathrm{ijt}}=\alpha_{0} \operatorname{Lnfdi}_{\mathrm{ijt}}+\beta_{0} \operatorname{Lntrade}_{\mathrm{ij}(\mathrm{t}-1)}+\beta_{1} \operatorname{Lnfdi}_{\mathrm{ij}(\mathrm{t}-1)}+\beta_{2} \operatorname{Lnexc}_{\mathrm{it}}$ $+\beta_{3}$ Lnpol $_{\mathrm{it}}+\mathrm{eu}+\mathrm{D}_{2008}+\varepsilon_{\mathrm{ijt}}$

Eşitlik (1) ve eşitlik (2)'de Lntrade ${ }_{\mathrm{ijt}}$, döneminde (2000-2018) Türkiye'nin en çok ticaret yaptığı 5 ülkeye (j) Türkiye'nin (i) ithalat ve ihracat miktarları toplamının doğal logaritmasıdır. Lnmig $_{\mathrm{ijt}}$ t döneminde, $\mathrm{i}$ ülkesinden $\mathrm{j}$ ülkelerine giden gösmen sayısını; yani Türkiye'den 2000-2018 yıllarında Türkiye'nin en çok ticaret yaptığ 5 ülkeye giden göçmen sayısının doğal logaritmasını ifade etmektedir. Lntrade $\mathrm{ij}_{\mathrm{ij}(\mathrm{t}-1)}, \mathrm{t}-1$ döneminde $\mathrm{i}$ ülkesinden $\mathrm{j}$ ülkesine yapılan toplam ticaretin logaritmasını; Lnmig $_{\mathrm{ij}(\mathrm{t}-1)}$, $\mathrm{t}-1$ döneminde $\mathrm{i}$ ülkesinde $\mathrm{j}$ ülkesine giden göçmen sayısının logaritmasını; Lnfdi ${ }_{\mathrm{ijt}}$, $\mathrm{t}$ döneminde i ülkesine $\mathrm{j}$ ülkesinden gelen doğrudan yabancı sermaye yatırımlarının logaritmasını; $\operatorname{Lnfdi}_{\mathrm{ij}(\mathrm{t}-1)}, \mathrm{t}-1$ döneminde i ülkesine j ülkesinden gelen doğrudan yabancı sermaye yatırımlarının logaritmasın1; Lnexc $_{\text {it }}$, t döneminde Euro/TL ve Dolar/TL kurunun logaritmasını; Lnempf $_{\mathrm{jt}}, \mathrm{t}$ döneminde $\mathrm{j}$ ülkesindeki yabancı doğumlu istihdam oranının doğal logaritmasını; Lngdp ${ }_{\mathrm{it}}$, döneminde j ülkesi GSYİH'sinin logaritmasını; Lnkof $\mathrm{j}_{\mathrm{j} \text { ' }}$ $\mathrm{t}$ döneminde $\mathrm{j}$ ülkesinin küreselleşme indeksinin logaritmasını; $\operatorname{Lnpol}_{\mathrm{jt}}, \mathrm{t}$ döneminde j ülkelesinin politik istikrar endeksinin doğal logaritmasını ifade etmektedir. Zamana göre değişmeyen değişken olan, Lndist ${ }_{\mathrm{ij}}$, $\mathrm{j}$ ülkelesinin sermaye şehirlerinin i ülkesinin sermaye şehirlerine olan coğrafi uzaklığıdır. Model-1 ve Model-2'de ortak yer alan eu (Avrupa Birliği’ne üye ülkeler için 1, diğerleri için 0 değerini alan) ve $\mathrm{D}_{2008}$ (Tüm ülkeler için 2008 ve 2009

1 Gao (2003), Tong (2005), Kugler ve Rappoport (2007), Javorcik ve ark. (2011), Foad (2012), Malan (2015) ve Garas ve ark. (2016) göçün FDI'ler üzerindeki anlamlı etkilerini ortaya koymaktadır. Bu iki değişkenin birbiri üzerindeki etkilerinin çoklu doğrusal bağlantı oluşturması nedeniyle, göç ve FDI akımları değişkeni iki farklı model içerisinde yer almıştır. 
y1llarında 1, diğer yıllarda 0 değerini alan) kukla değişkenlerdir. Son olarak, $\varepsilon_{\mathrm{ijt}}$ ise hata terimidir.

Emek hareketinin göç akımlarında temel özne olması nedeniyle emek hareketliliği göç bağlamında incelenmiştir. Sermaye hareketleri ise finansal yatırımları içermeyen, doğrudan yabancı sermaye yatırımları özelinde ele alınmıştır. Göçün ticaret üzerindeki etkisini açıklayan Model-1'de açıklayıcı değişkenlerin açıklanan değişken üzerindeki beklenen etkileri farklıdır. Göçün ticaret üzerindeki etkisi hem tercih hem de network kanallarıyla (Gould, 1994) pozitif yönlüdür. Bir dönem önce giden göçmenlerin de ticaretin cari dönemdeki değerini pozitif yönde etkilemesi beklenmektedir. Ticaretin cari değerleri geçmiş dönem ticaret değerlerinden büyük ölçüde etkilenmektedir. Bu manada ticaretin geçmiş değerlerinin cari dönem değerlerini pozitif yönde etkilemesi beklenmektedir. Döviz kurundaki azalma yabancılar için yurtiçi malları daha pahalı hale getirirken, uluslararası fiyat rekabetinde ticari gücü azaltıcı bir faktördür. Diğer bir deyişle, TL'nin yabancı paralar cinsinden fiyatı yükseldiğinde ihracatının artması beklenmektedir. Ülkeler arasındaki artan coğrafi uzaklık, taşıma ve işlem maliyetlerinin artması yönüyle ticareti azaltıcı etki doğurmaktadır. Göç edilen ülkelerdeki yabancı doğumluluların istihdam oranları, ülkelerin ekonomik büyüklükleri, politik istikrar durumları ve küreselleşme anlamındaki ilerlemeleri, Türkiye'den söz konusu ülkelere göç edecekler üzerinde pozitif yönde etkili olmaktadır ve göçmenlerin ticaret üzerindeki etkisini artırmaktadır.

Ticaretin bağımlı değişken olarak yer aldığı Model-2'de, doğrudan yabanc1 yatırımlardaki artışın ticareti artırması beklenirken; bir dönem önceki doğrudan yabancı yatırımların ve ticaret değerinin de cari ticareti pozitif yönde etkilemesi beklenmektedir. Döviz kuru ve doğrudan yabancı yatırımlar arasındaki ilişkinin yönü yatırımın faize duyarlılığı ve diğer makro ekonomik değişkenlerde oluşturacağ1 etki nedeniyle pozitif ve negatif yönde olabilmektedir. Doğrudan yabancı yatırımların gideceği ülkelerin politik istikrar durumu oldukça önemlidir. Politik istikrardaki bir artış doğrudan yabancı yatırımlardaki artışa olanak tanımaktadır. 
Tablo 1

Değisskenlerin Tanımları ve Veri Kaynakları

\begin{tabular}{|c|c|c|}
\hline Değişkenler & Tanımları & $\begin{array}{c}\text { Veri } \\
\text { Kaynakları }\end{array}$ \\
\hline $\operatorname{mig}_{\mathrm{ij}}$ & $\begin{array}{l}\text { Türkiye'nin hacim olarak en yoğun ticaret yaptığ ülkelere 2000- } \\
2018 \text { yıllarında giden göçmenlerin sayısının doğal logaritması }\end{array}$ & OECD.stat \\
\hline $\operatorname{trade}_{i j}$ & $\begin{array}{l}\text { Türkiye'nin hacim olarak en yoğun ticaret yaptığ ülkelere } \\
2000-2018 \text { y1llarında gerçekleştirdiği ihracat ve ithalat miktar1 } \\
\text { toplamlarının doğal logaritması }\end{array}$ & OECD.stat \\
\hline $\mathrm{exc}_{\mathrm{i}}$ & $\begin{array}{l}\begin{array}{l}\text { Euro/TL ve Dolar/TL kurunun 2000-2018 yıllarındaki y1llık } \\
\text { ortalama değerinin doğal logaritmas1 }\end{array} \\
\end{array}$ & TCMB \\
\hline $\operatorname{dist}_{\mathrm{ij}}$ & $\begin{array}{l}\text { Türkiye'nin hacim olarak en yoğun ticaret yaptığı ülkelerin sermaye } \\
\text { şehirleri ile İstanbul ve Ankara'ya olan ortalama coğrafi uzaklığının } \\
\text { doğal logaritması }\end{array}$ & CEPII \\
\hline eu & $\begin{array}{l}\text { Türkiye'nin hacim olarak en yoğun ticaret yaptığı ülkelerden } \\
\text { Avrupa Birliği'ne üye olan ülkeler'in 1, olmayan ülkelerin } 0 \\
\text { değerini aldığ } 1 \text { kukla değişken }\end{array}$ & \\
\hline D2008 & $\begin{array}{l}\text { Küresel krizin etkilerini modele dahil etmesi açısından } 2008 \text { ve } \\
2009 \text { y1lları için oluşturulmuş kukla değişken }\end{array}$ & \\
\hline $\operatorname{empf}_{j}$ & $\begin{array}{l}\text { Türkiye'nin hacim olarak en yoğun ticaret yaptığı ülkelerdeki 2000- } \\
2018 \text { yıllarındaki yabancı milletten olanların istihdam oranının } \\
\text { doğal logaritması }\end{array}$ & OECD.stat \\
\hline $\operatorname{gdp}_{\mathrm{j}}$ & $\begin{array}{l}\text { Türkiye'nin hacim olarak en yoğun ticaret yaptığ ülkelerin 2000- } \\
2018 \text { yıllarındaki sabit fiyatlarla \$ cinsinden } 2010 \text { yıl bazlı kişi } \\
\text { başına düşen GSYIH değerinin doğal logaritması }\end{array}$ & OECD.stat \\
\hline kof $_{j}$ & $\begin{array}{l}\text { Küreselleşmenin ekonomik, sosyal ve politik boyutlarını ölçen KOF } \\
\text { Küreselleşme Endeksi'nin 2000-2018 yıllarındaki değerlerinin } \\
\text { doğal logaritması. }\end{array}$ & $\begin{array}{l}\text { KOF Swiss } \\
\text { Economic } \\
\text { Institute }\end{array}$ \\
\hline pol $_{\mathrm{j}}$ & $\begin{array}{l}\text { Türkiye'nin hacim olarak en yoğun ticaret yaptığı ülkelerin 2000- } \\
2018 \text { yıllarındaki politik sürdürülebilirlik indeksinin (-2.5 ve } 2.5 \\
\text { aralığında tahmin edilen ) doğal logaritması }\end{array}$ & World Bank \\
\hline $\mathbf{f d i}_{\mathrm{ij}}$ & $\begin{array}{l}\text { Türkiye'nin hacim olarak en yoğun ticaret yaptığı ülkelerden } 2000 \text { - } \\
2018 \text { yıllarında Türkiye'ye gelen doğrudan yabancı yatırımların } \\
\text { doğal logaritması }\end{array}$ & OECD.stat \\
\hline
\end{tabular}

Tablo 2

Model-1 Değişkenlerin Özet İstatistikleri

\begin{tabular}{|l|c|c|c|c|}
\hline Değişkenler & Ortalama & Standard Sapma & En Düşük & En Yüksek \\
\hline mig $_{\mathbf{i j}}$ & 8.402 & 1.246 & 6.549 & 10.970 \\
\hline trade $_{\mathbf{i j}}$ & 21.388 & 1.097 & 19.680 & 23.604 \\
\hline exc $_{\mathbf{i}}$ & 0.694 & 0.481 & -0.555 & 1.733 \\
\hline dist $_{\mathbf{i j}}$ & 7.877 & 0.598 & 7.224 & 8.996 \\
\hline eu $^{\mathbf{D 2 0 0 8}}$ & 0.8 & 0.402 & 0 & 1 \\
\hline empf $_{\mathbf{j}}$ & 0.105 & 0.308 & 0 & 1 \\
\hline gdp $_{\mathbf{j}}$ & 4.150 & 0.084 & 3.955 & 4.300 \\
\hline kof $_{\mathbf{j}}$ & 15.070 & 0.748 & 14.470 & 16.697 \\
\hline pol $_{\mathbf{j}}$ & 4.430 & 0.043 & 4.340 & 4.495 \\
\hline fdi $_{\mathbf{i j}}$ & -0.746 & 0.677 & -3.284 & 0.345 \\
\hline
\end{tabular}


Model-1'de yer alan değişkenlerin ortalama, standart sapma, en düşük ve en yüksek değerleri Tablo-2'de verilmiştir. Ortalaması en düşük pol ${ }_{j}$ iken, en yüksek ortalama değer trade ${ }_{\mathrm{ij}}$ değişkenidir. Standart sapması en yüksek ve en düşük değişkenler sırasıyla mig $_{\mathrm{ij}}$ ve empf ' ${ }_{\mathrm{j}}$ dir.

Tablo 3

Model-1 Değişkenlere Ait Korelasyon Matrisi

\begin{tabular}{|c|c|c|c|c|c|c|c|c|}
\hline & trade $_{i j}$ & mig $_{i j}$ & $\operatorname{exc}_{i}$ & dist $_{i j}$ & empf $_{j}$ & $\operatorname{gdp}_{j}$ & kof $_{j}$ & pol $_{i}$ \\
\hline trade $_{i j}$ & 1.000 & & & & & & & \\
\hline $\operatorname{mig}_{i j}$ & 0.263 & 1.000 & & & & & & \\
\hline exc $_{i}$ & 0.826 & 0.047 & 1.000 & & & & & \\
\hline dist $_{i j}$ & -0.090 & 0.071 & -0.143 & 1.000 & & & & \\
\hline empf $_{j}$ & 0.225 & -0.082 & 0.160 & 0.535 & 1.000 & & & \\
\hline $\operatorname{gdp}_{j}$ & 0.046 & 0.153 & -0.073 & 0.936 & 0.582 & 1.000 & & \\
\hline kof $_{j}$ & 0.448 & 0.303 & 0.452 & -0.0320 & -0.102 & -0.455 & 1.000 & \\
\hline pol $_{i}$ & -0.156 & 0.325 & -0.428 & -0.098 & -0.098 & -0.005 & -0.060 & 1.000 \\
\hline
\end{tabular}

Model-1'deki değişkenlerin birbirleri ile olan korelasyonu Tablo-3'de görüldüğü üzere; mig $_{\mathrm{ij}}$, trade ${ }_{\mathrm{ij}}$ 'deki değişimin \%26sını pozitif yönlü orarak açıklamaktadır. Yine exc $_{\mathrm{i}}$, trade $_{\mathrm{ij}}{ }^{\prime}$ deki değişimin \%82'sini pozitif yönlü olarak açıklamaktadır. empf ${ }_{\mathrm{j}}$ gdp $_{\mathrm{j}}$ ve kof $_{\mathrm{j}}$ değişkenleri trade ${ }_{\mathrm{ij}}$ değişkenini sırasıyla \%22, $\% 04$ ve \%44 oranında pozitif yönde açıklamaktadır. dist ${ }_{i j}$ ve pol $_{j}$ değişkenleri sırasıyla negatif yönde trade ${ }_{\mathrm{ij}}$ değişkenini \%09 ve \%15 oranında açıklamaktadır.

Tablo 4

Model-2 Değişkenlere Ait Korelasyon Matrisi

\begin{tabular}{|l|c|c|c|c|}
\hline & trade $_{i j}$ & $\mathbf{f d i}_{i j}$ & exc $_{i}$ & pol $_{j}$ \\
\hline trade $_{i j}$ & 1000 & & & \\
\hline fdi $_{i j}$ & 0.068 & 1.000 & & \\
\hline exc $_{i}$ & 0.826 & 0.067 & 1.000 & \\
\hline pol $_{j}$ & -0.156 & 0.125 & -0.428 & 1.000 \\
\hline
\end{tabular}

Model-2'deki değişkenlerin birbirleri arasındaki ilişkiyi yansıtan korelasyon matrisi Tablo-4' de verilmiştir. Buna göre en yüksek korelasyon pozitif yönlü olarak $\operatorname{exc}_{\mathrm{i}}$ ve trade ${ }_{\mathrm{ij}}$ arasında bulunmaktadır ve trade $_{\mathrm{ij}}$ 'deki değişimin \%06's $\mathrm{fdi}_{\mathrm{ij}}$ değişkenince açıklanmaktadır. Tablo-2, Tablo-3 ve Tablo-4'de değişkenlere ait özet bilgiler ve birbirleriyle olan ilişkiler yorumlanabilmektedir. Bu bilgiler değişkenler ve aralarındaki ilişkilere yönelik önsel bilgiler sağlamaktadır, ancak semaye hareketlerinin ve göçün ticaret üzerindeki etkisinin uygun tahmin yöntemleriyle test edilmesi daha etkin sonuçların elde edilmesine yardımcı olacaktır.

Panel veriye dayalı analizler, hem yatay kesit hem de zaman serinin birlikte kullanılmasıyla daha fazla veriyle çalışma imkanı sunmaktadır. Ayrıca artan 
serbestlik derecesi açıklayıcı değişkenler arasındaki çoklu bağlantıyı azaltmakta ve tahmin sonuçlarının tutarlı olmasına olanak sunmaktadır (Hasio, 2003, s. 8). Yatay kesit verilerin analizinde ortaya çıkan heterojenlik problemi birim ve zaman etkilerin modele dahil edilmesiyle büyük oranda çözülmektedir. Panel veri, birim ve birimler arasındaki farklılıkların etkisini eş zamanda ortaya koyduğu için araştırmacılar tarafından çokça tercih edilmektedir (Yerdelen, 2016, s. 10). İktisadi modellerde yer alan değişkenlerin cari değerleri çoğu zaman geçmiş değerlerinden bağımsız düşünülememektedir. İktisadi ilişkilerin araştırılmasında bağımlı ve bağımsız değişkenlerin gecikmeli değerlerinin bağımsız değişken olarak modelde yer almasıyla dinamik panel veri modelleri statik modellerden farklılaşmaktadır. Bağımlı değişkenin bir dönem gecikmesi ile otoregresif panel veri modeli şu şekildedir:

$$
\mathrm{Y}_{\mathrm{it}}=\delta \mathrm{Y}_{\mathrm{it}-1}+\beta \mathrm{X}_{\mathrm{it}}^{\prime}+\mu_{\mathrm{i}}+\mathrm{u}_{\mathrm{it}}
$$

(3)'deki modelin geleneksel tahmin yöntemleri ile tahmininde bağımlı değişkenin gecikmeli değerinin modelde yer alması nedeniyle içsellik problemi; gecikmeli değerin birim etkilerin de bir fonksiyonu olması ve hata teriminin $\mu_{\mathrm{i}}^{\prime}$ 'yi içermesinden dolayı gecikmeli değer ile hata terimi arasındaki korelasyon katı dışsallık varsayımını sağlamayarak tahmincilerin sapmalı ve tutarsız olmasına neden olmaktadır. Dinamik panel veri modeli birim ve zaman etkilerini içeriyorsa havuzlanmış en küçük kareler yöntemi ile tahmin edildiğinde de içsellik problemi ortaya çıkmakta ve parametre tahminleri sapmalı olmaktadır. Balestra ve Nerlove (1966), gecikmeli bağımlı değişken ile hata terimi arasındaki korelasyonun araç değişken kullanımı ile kontrol edilmesini önermektedir. $\mathrm{Bu}$ tahminci içsellik probleminden kaynaklanan sapmayı azaltmasına ragmen, birim ya da zaman etkilerinin bulunduğu modellerde sapmalı sonuçlar vermektedir. Bundan dolayı dinamik panel veri modellerinin tahmininde birim etkileri dikkate alan ve birim etkiler ile bağımsız değişkenlerin korelasyonlu olmasına müsade eden sabit etkiler ve birinci fark tahmincileri gündeme gelmektedir (Yerdelen, 2018, s. 119). Ancak Nickell (1981), birim sayısının zaman boyutundan büyük olduğu hallerde sabit etkiler tahmincisinde oluşan sapmaya dikkat çekmiştir. Birinci fark tahmincisi ile dinamik panel veri modellerinin tahmininde yapılan birinci fark dönüşümü ile birim etki modelden düşmektedir. Ancak bağımlı değişkenin gecikmeli değerleri hata terimleri ile korelasyonlu olması nedeniyle elde edilen sonuçlar sapmalıdır. Bu nedenle birinci fark dönüşümü sonrasında içselliğin ortadan kalkması için araç değişken 
kullanımı ile içselliğin kontrol edilmesi önerilmektedir (Anderson ve Hasio, 1982). Bu tahmincinin elde ettiği sonuçlar tutarlı olmasına rağmen tüm moment şartlarını dikkate almaması ve otokorelasyon problemi nedeniyle etkin değildir. Birinci fark hata terimlerinin negatif otokorelasyonlu olduğu durumlarda Arellano ve Bond (1991), Genelleştirilmiş Momentler (GMM) tahmincisinin kullanımını önermektedir. Birinci fark modeli araç değişken kullanılarak dönüştürülmekte ve daha sonra model en küçük kareler yöntemi ile tahmin edilmektedir. (4). eşitlikteki dinamik modelde birinci fark ile birim etki modelden düşürülmüştür.

$$
\mathrm{Y}_{\mathrm{it}}-\mathrm{Y}_{\mathrm{it}-1}=\delta\left(\mathrm{Y}_{\mathrm{it}-1}-\mathrm{Y}_{\mathrm{it}-2}\right)+\left(\mathrm{u}_{\mathrm{it}}-\mathrm{u}_{\mathrm{it}-1}\right)
$$

(4). eşitlikte $\mathrm{Y}_{\mathrm{it}-1}, \mathrm{u}_{\mathrm{it}-1}$ ile korelasyonlu; hata terimi $\left(\mathrm{u}_{\mathrm{it}}-\mathrm{u}_{\mathrm{it}-1}\right)$ durağan değildir. Bu durumda $\left(\mathrm{Y}_{\mathrm{it}-1}-\mathrm{Y}_{\mathrm{it}-2}\right)$ için uygun araç değişken seçimi bağımlı değişkenin gecikmeli değerleri olmaktadır. $\mathrm{T}=4$ için;

$$
\mathrm{Y}_{\mathrm{i} 4}-\mathrm{Y}_{\mathrm{i} 3}=\delta\left(\mathrm{Y}_{\mathrm{i} 3}-\mathrm{Y}_{\mathrm{i} 2}\right)+\left(\mathrm{u}_{\mathrm{i} 4}-\mathrm{u}_{\mathrm{i} 3}\right)
$$

(5). eşitlikte $\left(\mathrm{Y}_{\mathrm{i} 3}-\mathrm{Y}_{\mathrm{i} 2}\right)$ ile yüksek korelasyona sahip, $\left(\mathrm{u}_{\mathrm{i} 4}-\mathrm{u}_{\mathrm{i} 3}\right)$ ile korelasyonlu olmayan $Y_{i 1}$ ve $Y_{i 2}$ uygun araç değişken olarak düşünülebilmektedir. Araç değişken matrisi $Z_{i}$ olarak düşünülecek olursa GMM tahmincisi aşağıdaki gibidir.

$$
\hat{\delta}_{G M M}=\left(\Delta X^{\prime} Z\left(Z^{\prime} \hat{\Omega} Z\right)^{-1} Z^{\prime} \Delta X\right)^{-1}\left(\Delta X^{\prime} Z\left(Z^{\prime} \hat{\Omega} Z\right)^{-1} Z^{\prime} \Delta Y\right)
$$

(6). eşitlikte hata teriminin varyans kovaryans matrisi $\hat{\Omega}$ 'dir.

Arellano ve Bond (1991) tahmincisi, birim hata varyansının artık hata varyansına oranı çok yüksek olduğunda, dengesiz panellerde veri kaybının en aza indirilmesinde ve otoregresif parametre sayısının çok fazla olduğu durumlarda zayıf kalmaktadır. Arellano ve Bover (1995), Sistem GMM tahmincisini önermiştir ve bu tahminci 'ortogonal sapmalar' yöntemine vurgu yapmaktadır. Dinamik panel veri modelinin sistem GMM tahmin yöntemi ile tahmin edilmesinde değişkenin gecikmeli değerlerinin kullanılması yerine bu değişkenlerin olası gelecek değerlerinin ortalamasının farkı kullanılmaktadır.

\section{Bulgular}

Dinamik panel veri modelinin farklı tahmin teknikleriyle tahmini, avantaj ve dezavantajları model ve yöntem bölümünde anlatılmıştır. Göçün ve doğrudan 
yabancı sermaye yatırımlarının ticaret üzerindeki etkisini ortaya koyan sistem GMM tahmin yöntemi sonuçları Tablo-5 ve Tablo-6'da verilmiştir.

Tablo 5

Model-1'den Elde Edilen Panel GMM Sonuçları

\begin{tabular}{|c|c|c|}
\hline Variables & Katsayı & Dirençli Standard Hatalar \\
\hline L.trade $_{\mathrm{ij}}$ & $0.318^{* * *}$ & 0.031 \\
\hline mig $_{i j}$ & $0.146^{* * *}$ & 0.058 \\
\hline L.mig ${ }_{i j}$ & 0.031 & 0.081 \\
\hline $\operatorname{exc}_{i}$ & $1.452 * * *$ & 0.082 \\
\hline dist $_{i j}$ & $-1.388 * * *$ & 0.335 \\
\hline eu & $-3.268 * * *$ & 1.086 \\
\hline D2008 & $-0.200 * * *$ & 0.035 \\
\hline empf $_{j}$ & 0.535 & 0.551 \\
\hline $\operatorname{gdp}_{j}$ & -0.452 & 0.352 \\
\hline kof $_{j}$ & $6.843 * * *$ & 1.833 \\
\hline pol & $0.097 * * *$ & 0.029 \\
\hline Observation & 94 & \\
\hline AR(1), P-value & -2.11 & 0.035 \\
\hline AR(2), P-value & -0.89 & 0.373 \\
\hline Sargan, P-value & 3.08 & 0.079 \\
\hline
\end{tabular}

Not: Bağımlı değişken trade ${ }_{\mathrm{ij}}{ }^{\prime}{ }^{\mathrm{dir}}$. ${ }^{* * * \% 1} \%$ anlamlılık düzeyi, $* * \% 5$ anlamlılık düzeyi, *\%10 anlamlılık düzeyini ifade etmektedir.

Göçün tiracet üzerindeki etkisini tespit etmek için oluşturulan panel veriye dayalı Model-1, sistem GMM tahmin yöntemi yardımıyla test edilmiştir. Panel GMM tahmin sonuçları Tablo-5'de verilmiştir. L.trade ${ }_{\mathrm{ij}}$, mig $_{\mathrm{ij}}$, exc $_{\mathrm{i}}$, dist $\mathrm{ij}_{\mathrm{ij}}$, eu, $\mathrm{D}_{2008}$, kof $_{\mathrm{j}}$ ve pol $_{\mathrm{j}}$ değişkenleri Türkiye'nin en büyük ticaret orataklarıyla olan ticaretini açıklamakta anlamlıdır. L.trade ${ }_{\mathrm{ij}}{ }^{\mathrm{d}} \mathrm{de} \% 1$ 'lik $\operatorname{artış~trade~}_{\mathrm{ij}}{ }^{\mathrm{i}} \mathrm{i} \% 0.31$ oranında artırmaktadır. mig $_{\mathrm{ij}}{ }^{\prime}$ 'nin $\% 1$ artması trade ${ }_{\mathrm{ij}}{ }^{\prime} \mathrm{i} \% 0.14$ oranında artırmaktadır. exc ${ }_{\mathrm{i}}$ değişseninin \%1'lik artışı trade ${ }_{\mathrm{ij}}{ }^{\prime} \mathrm{i} \% 1.45$ oranında

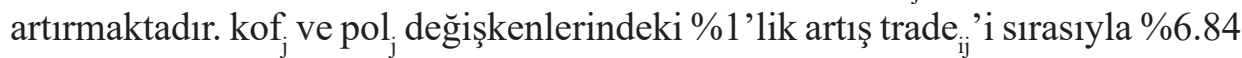
ve $\% 0.09$ oranında artırmaktadır. Teorik beklentiyle uyumlu olarak, dist ${ }_{\mathrm{ij}}{ }^{\prime}$ deki $\% 1$ 'lik artış trade ${ }_{\mathrm{ij}}{ }^{\prime} \mathrm{i} \% 1.38$ oranında azaltmaktadır. 
Tablo 6

Model-2'den Elde Edilen Panel GMM Sonuçları

\begin{tabular}{|l|c|c|}
\hline Variables & Katsayı & Dirençli Standard Hatalar \\
\hline L.trade $_{i j}$ & $0.935^{* * *}$ & 0.016 \\
\hline fdi $_{i j}$ & $0.109^{* *}$ & 0.050 \\
\hline L.fdi $_{i j}$ & 0.024 & 0.017 \\
\hline exc $_{i}$ & $0.936^{* * *}$ & 0.152 \\
\hline eu & -0.020 & 0.092 \\
\hline D2008 & $-0.166^{* * *}$ & 0.049 \\
\hline polj & -0.036 & 0.093 \\
\hline Observation & 94 & 0.027 \\
\hline AR(1), P-value & -2.22 & 0.672 \\
\hline AR(2), P-value & 0.42 & 1.000 \\
\hline Hansen, P-value & 0.00 & \\
\hline
\end{tabular}

Not: Bağımlı değişken trade ${ }_{\mathrm{ij}}$ 'dir. *** \%1 anlamlılık düzeyi, ** \%5 anlamlılık düzeyi, * \%10 anlamlılık düzeyini ifade etmektedir.

Doğrudan yabancı sermaye yatırımlarının ticaret üzerindeki etkisini ortaya koyan Model-2'nin Sistem GMM tahmin sonuçları Tablo-6'da verilmiştir. Elde edilen sonuçlara göre; L.trade ${ }_{\mathrm{ij}}$, $\mathrm{fdi}_{\mathrm{ij}}$, exc $_{\mathrm{i}}$ ve $\mathrm{D}_{2008}$ değişkenleri Türkiye'nin en çok ticaret yaptığı ülkeler ile olan ticaretini açıklamakta anlamlı bulunmuştur. fdi $_{\mathrm{ij}}{ }^{\prime}$ deki \% 1 artış ticareti \%0.10 artırmaktadır. L.trade ${ }_{\mathrm{ij}}$ ve exc $_{\mathrm{i}}$ değişkenlerindeki $\% 1$ artış trade $_{\mathrm{ij}}$ 'yi \%0.93 artırmaktadır.

Sistem GMM tahmin sonuçlarının etkinliği için önemli olan AR(1) test sonucunun (birinci mertebeden otokorelasyonun) negatif yönde otokorelasyon bulunması ve ikinci mertebeden otokorelasyon bulunmaması yönündedir. Tablo-5 ve Tablo-6'nın Panel GMM tahmininden elde edilen otokorelasyon sonuçları beklentiyle uyumludur. İki modelde de birinci mertebeden negatif otokorelasyon varken, ikinci mertebeden otokorelasyon bulunmamaktadır. Genelleştirilmiş momentler tahmininde kullanılan araç değişkenlerin geçerli olup olmadığ Arellano ve Bond (1991) tarafından önerilen Sargan testi ve Dirençli Hansen testleri ile sınanmaktadır. Tablo-5 ve Tablo-6'daki Sargan ve Dirençli Hansen test sonucuna göre aşırı tanımlama kısıtlamalarının geçerli olduğunu ifade eden temel hipotez reddedilememektedir. Bu durumda aşırı tanımlama kısıtlamaları geçerlidir. Yani kullanılan araç değişkenlerin geçerliliği bulunmaktadır. Elde edilen bulgular sistem GMM tahmin yöntemin geçerliliğini ortaya koymaktadır. 


\section{Sonuç}

Faktör Donatımı Teorisi adıyla Heckscher-Ohlin tarafından uluslararası ticaret literatürüne kazandırılan yaklaşım, karşılaştırmalı üstünlükler teorisininin temel varsayımlarına bağlı olarak ülkeler arasındaki dış ticaret ilişkilerinin ülkelerin bulundurdukları emek ve sermaye olmak üzere bol olan faktöre göre gerçekleştiğine vurgu yapmaktadır. Faktör donatımı teoremi sonrasında geliştirilen faktör fiyatlarının eşitliği teoremi ve Vernon (1966) tarafından geliştirilen ürün dönemleri teorisi faktör hareketleri ve ticaret arasındaki ilişkiye değinen başlıca teoriler olarak literatürde yerini almaktadır. Faktör hareketliliği, emek ve sermaye bağlamında ele alındığında, göç hareketleri emek hareketinin; doğrudan yabancı sermaye yatırımları da sermaye hareketliliğinin genel bir durumunu yansıtmaktadır. Bu bilgi ışığında, faktör hareketleri göç ve DYY olarak ele alınırken, bunların ticaret üzerindeki etkisi iki farklı dinamik panel veri modeli oluşturularak karşılaştırmalı olarak analiz edilmiştir.

2000-2018 y1llarında Türkiye'nin en büyük ticari partner ülkelerine Türkiye'den giden göçmenlerin ticaret üzerindeki etkisinin modellendiği Model-1 sonuçları ticaretin gecikmeli ticaret, giden göçmenler, uzaklık, döviz kuru, politik istikrar, küreselleşme seviyesi tarafından açıklandığını göstermektedir. Türkiye'nin en büyük ticari partner ülkelerinden Türkiye'ye gelen DYY'lerin ticaret üzerindeki etkisinin modellendiği Model-2 sonuçları ticaretin geçmiş dönem ticaret değeri, doğrudan yabancı yatırımlar ve döviz kuru tarafından açıklandığını göstermektedir. Model-1 ve Model-2'den elde edilen tahmin sonuçlarına göre; Türkiye'nin söz konusu 5 ülke ile olan toplam ticarette Türkiye'den bu ülkelere giden göçmenlerin etkisi, Türkiye'ye bu ülkelerden gelen doğrudan yabancı yatırımlardan daha etkilidir. Türkiye'den Almanya, ABD, İtalya, Fransa ve Birleşik Krallık ülkelerine giden göçmenlerdeki ve bu ülkelerden Türkiye'ye gelen doğrudan yabancı sermaye yatırımlarındaki \%1'lik artış Türkiye'nin bu ülkeler ile olan toplam ticaretini sırasıyla $\% 0.14$ ve $\% 0.10$ oranında artırmaktadır. Giden göçmenlerin ticaret üzerindeki pozitif etkiler doğurduğu sonucu Gould (1994), Hied ve Ries (1998), Dunlevy ve Hutchinson (1999), Dunlevy ve Hutchinson (2001), Rauch ve Trindade (2002) Combes vd. (2002), Girma ve Yu (2002), Wagner vd., (2002) ve Egger vd. (2011) çalışmalarının sonuçları ile benzerlik taşımaktadır. DYY'lerin ticareti pozitif etkilediği sonucu Kojima (1991), Buigues ve Jacquemin (1994), Liu ve Graham (1998), Pantulu ve Poon (2003) ve Aizenmana ve Noyb (2006) çalışmalarının bulgularıyla örtüşmektedir. 
Türkiye'de 2019-2023 döneminde uygulanması öngörülen ekonomik hedef planlar ve politikların ortaya konulduğu 11. Kalkınma Planında, rekabetçiliği ve verimliliği artırıcı politikalar temelinde dış ticarette ihracatın artırılması ve ithalat bağımlılı̆̆ının azaltılmasını amacına uygun olarak ihracat odaklı dönüşüm hedeflenmektedir. Bu bağlamda GSYİH'ye katkısı açısından sanayi sektörünün payının artırılması ve uluslararası doğrudan yatırımların özellikle sanayi sektörüne çekilmesi ve komple yeni yatırımların payının artırılması açıça hedeflenmektedir. Bu konuda küresel ekonomik ivme kaybı ve pandemiye bağlı olarak belirsizlik ortamının getirdiği yavaşlama eğilimi tehdit olarak algılanabilecekse de; Türkiye Dünya Bankası'nın iş yapma kolaylı̆̆g endeksinde 2014 yılında 189 ülke arasında 51. sırada iken, 2020 yılında 190 ülke arasında 33. sıraya yükselmiştir. İmalat sanayiinde yüksek katma değer yaratan komple yeni yatırımların ülkemize çekilmesi noktasında DYY'lerin ticaret artırıcı etkisinin de değerlendirilmesi önem arz etmektedir. 11. Kalkınma Planı'nda üzerinde durulan diğer bir husus göç olgusudur. Küreselleşmeyle birlikte artan göçün, emek arzının önemli bir unsuru haline geldiği, artan göçle beraber göç alan-veren ülkelerin ve transit ülke ayrımlarının belirsizleştiği vurgulanmakadır. Göç hareketlerinin Türkiye'nin ticaretinde ve özellikle de ihracatında oluşturacağı pozitif etki politika yapıcılar tarafından göz önünde bulundurulmalıdır. Türkiye'den giden göçmenlerin anavatanları ile bağlarını devam ettirecek network kanallarının gerek bireysel gerek kurumsal örgütlenmeler yoluyla açık tutulması, Türkiye'nin nihai ekonomik hedeflerinden olan ticaret ve ihracatın artırılmasına katkı sunacaktır.

Elde edilen bulgular, Türkiye'nin ticaretinin geliştirilmesi noktasında öngörülen ticari politikalarda doğrudan yabancı yatırım ve göç etkisinden kaynaklanan pozitif etkinin artırılabilme imkanına vurgu yapmaktadır. Çalışmamız dış ticaret, göç ve doğrudan yabancı yatırım gibi değişkenlerin makro verilerinden faydalanarak uygulamalı analizini gerçekleştirmiştir. Türkiye'nin güncel ekonomi politikaları, katma değeri yüksek mal ihracatının artırılması ve ara malı ithalat bağımlılığının aşamalı olarak azaltılması temel hedefleri doğrultusunda, söz konusu ülkelere gerçekleşen sektör ve ürün bazında sınıflandırılmış ticaret verileri ışığında faktör hareketliliğinin incelenmesi çalışmanın kapsayıcılığını artıracaktır. 
Hakem Değerlendirmesi: Dış bağımsız.

Çıkar Çatışması: Yazar çıkar çatışması bildirmemiştir.

Finansal Destek: Yazar bu çalışma için finansal destek almadığını beyan etmiştir.

Peer-review: Externally peer-reviewed.

Conflict of Interest: The author has no conflict of interest to declare.

Grant Support: The author declared that this study has received no financial support.

\section{Kaynakça/References}

Aizenman, J., Noy, I. (2006). FDI and trade-two-way linkages?, The Quarterly Review of Economics and Finance, 46(3), 317-337, Erişim tarihi: 01.02.2021, https://doi. org/10.1016/j.qref.2006.02.004

Anderson, T. W., Hasio, C. (1982). Formulation and estimation of dynamic models using panel data, Journal of Econometrics, 18(1), 47-82.

Arellano, M., Bond, S. (1991). Some tests of specification for panel data: monte carlo evidence and an application to employment equations, Review of Economic Studies, 58(2), 277-297.

Arellano, M., Bover, O. (1995). Another look at the instrumental variable estimation of error-components models, Journal of Econometrics, 68(1), 29-51.

Balestra, P., Nerlove, M. (1966). Pooling cross section and time series data in the estimation of a dynamic model: the demand for natural gas. The Econometric Society, 34(3), 585-612.

Baldwin, R., Venables, A. J. (1994). International migration, capital mobility and transitional dynamics, Economica, 61(243), 285-300.

Brainard, S. L. (1995). An empirical assessment of the proximity-concentration tradeoff between multinational sales and trade. National Bureau of Economic Research Working Paper No. 4580.

Buigues, P., Jacquemin, A. (1994). Foreign direct investment and exports to the European community. Oxford and New York: The Oxford University Press.

Combes, P. P., Lafourcade, M., \& Mayer, T. (2005). The trade creating effects of business and social networks: evidence from France. Journal of International Economics, $66(1), 1-29$.

Dunlevy, J.A., Hutchinson, W. K. (1999). The impact of immigration on American import trade in the late nineteenth and early twentieth centuries. Journal of Economic History, 59(4) 1043-1062.

Dunlevy, J.A., Hutchinson, W. K. (2001). The pro-trade effect of immigration on American exports during the late nineteenth and early twentieth centuries. IZA Discussion Paper: 375.

Egger, P. H., Enrlich, M., \& Nelson, D.R. (2011). Migration and trade. The World Economy, 35(2), 216-241. 
Girma, S., Yu, Z. (2002). The link between immigration and trade: evidence from the United Kingdom. Review of World Economics, 138(1), 115-30.

Gould, D. M. (1994). Immigrant links to the home country: empirical implications for U.S. bilateral trade flows. Review of Economics and Statistics, 76, 302-316.

Gonzalez, P. A., Maloney, W. F. (2005). Migration, trade, and foreign direct investment in Mexico. The World Bank, Erişim Tarihi: 01.03.2021, https://openknowledge. worldbank.org/handle/10986/8930

Hasio, C. (2003). Analysis of panel data (2. Bask1), UK: Cambridge Universty Press.

Head, K., Ries, J. (1998). Immigration and trade creation: econometric evidence from Canada. Canadian Journal of Economics, 31, 47-62.

Helpman, E., Krugman, P. (1985). Market structure and foreign trade. Cambridge, MA: MIT Press

Kojima K. (1978) Direct foreign investment: Japanese Model versus American model Kojima (ed.) Direct foreign investment: A Japanese model of multinational business operations (pp: 83-102), New York: Praeger Publishers.

Kojima, K. (1991). A Pacific economic community in a new international order. Singapore Economic Review, 36(2), 1-12.

Liu, L.G., Graham, E. M. (1998). The relationship between trade and foreign investment: empirical results for Taiwan and South Korea, Peterson Institute for International Economics, Working Paper 98-7.

Martin, P. L. (1993). Trade and migration: NAFTA and agriculture. Institute for International Economics, Retrived from Schiff, M. (1996, December), South-north migration and trade, The World Bank, Policy Research. Working Paper 1696.

Markusen, J. R. (1983). Factor movements and commodity tade as complements, Journal of International Economics, 14(3-4), 341-356.

Mundell, R. A. (1957). International trade and factor mobility. The American Economic Review, 47(3), 321-335.

Nickell, S. (1981). Biases in dynamic models with fixed effects, Econometrica, 49(6), 1417-1426.

Pantulu, J., Poon, J.P.H. (2003). Foreign direct investment and international trade: evidence from the US and Japan. Journal of Economic Geography, 3(3), 241-259, Erişim Tarihi: 09.012021, https://doi.org/10.1093/jeg/3.3.241

Rauch, J. E., Tridade, V. (2002). Ethnic Chinese networks in international trade. The Review of Economics and Statistics, 84(1), 116-130.

Russell, S. S., Teitelbaum, M. S. (1992). International migration and international trade. World Bank Discussion Paper, 160. Washington. USA.

Samuelson, P. A. (1949). International trade and the equalization of factor prices, The Economic Journal, 58(230), 163-184. 
Vernon, R. (1966). International investment and international trade in the product cycle. Quarterly Journal of Economics, 80, 190-207.

Wagner, D., Head, K., \& Ries, J. (2002). Immigration and the trade of provinces", Scottish Journal of Political Economy, 49(5), 507-525.

Yerdelen Tatoğlu, F. (2018). Ileri panel veri analizi (3. Baskı). İstanbul: Beta Yayıncılık. 